\title{
Urgences
}

\section{Qui ose parler d'amour, moman? (dessin de Jacqueline Chénard)}

\section{Susane Hurtubise}

Numéro 6, 4e trimestre 1982

URI : https://id.erudit.org/iderudit/025088ar

DOI : https://doi.org/10.7202/025088ar

Aller au sommaire du numéro

Éditeur(s)

Urgences

ISSN

0226-9554 (imprimé)

1927-3924 (numérique)

Découvrir la revue

Citer ce document

Hurtubise, S. (1982). Qui ose parler d'amour, moman ? (dessin de Jacqueline

Chénard). Urgences, (6), 15-26. https://doi.org/10.7202/025088ar d'utilisation que vous pouvez consulter en ligne.

https://apropos.erudit.org/fr/usagers/politique-dutilisation/ 


\section{SUSANE HURTUBISE}

Qui ose parler d'amour, moman?

(dessin de Jacqueline Chénard) 


\section{QUI OSE PARLER D'AMOUR?}

Qui ose parler d'amour

devant cette femme éventrée

sur le trottoir des âmes hantées

Qui ose parler de désir

devant cette femme crucifiée nue

sur le cinéma des âmes seules

Qui ose parler de tendresse

devant cette femme surprotégée

coulée en douce dans le carcan muet du dévouement discret

Qui ose parler de reconnaissance

devant cette femme beurrée jusqu'à l'âme

soudée à l'image-mensonge de son miroir-confident

Qui ose parler de liberté

devant cette femme mise en boîte

enterrée d'enfants-surprises

clouée par le ventre au plancher d'cuisine qui tourne en rond

Qui ose parler d'amitié

devant cette femme folle

qui chavire le ventre noué de vide

s'enfermant dans un cercle vicieux

qui la coule dans le noeud coulant de la mort

Comment parler d'amour

devant toutes ces femmes-martyres

surprotégées beurrées mises en boîte

folles éventrées crucifiées

Comment parler d'amour

devant ces femmes-martyres

qui se tuent à s'effacer en douce

devant ces femmes qui se tuent à plaire

se tuent à faire

se tuent à s' taire

se tuent... se tuent... 
On n'est pas nées femmes-martyres

c'est pas une plainte

c'est une réalité qui veut parler

c'est pas une complainte

c'est une contrainte

c'est une tension dans l'dos

un poids sur la nuque

une crispation à la bouche

c'est une crampe

une crampe aux jambes

une crampe au ventre

une crampe au coeur

On n'est pas nées femmes-martyres

On nous a piégées depuis toujours

toi le grimaceur

j'ai ton klaxon creusé au tympan

tu jappes des p'tits mots ridicules

pis moi l'coeur m'étrangle

toi l'agresseur

j'ai ta poursuite le long d'la colonne

tu défoules ton mal au coeur au coin des rues

pis moi les jambes me tremblent

toi I'patron

j'ai ton approbation enfoncée dans ma pensée

j'ai ta signature dans l'front

ta signature sur'l'corps

ta signature dans l'corps

pis toi l'homme de la morale et de la loi

ta tête bien pensante sous-estime la mienne ton esprit borné administre les affaires de mon définit l'Oeuf /ventre juge mes entrailles détermine mon existence 
On n'est pas nées femmes-martyres

On nous a piégées depuis toujours

L'ENFANCE est restée prisonnière dans les griffes de

il faut déterrer l'ENFANT-FEMME

/la PEUR

enfouie sous le silence

sacrifiée sur les bancs de l'école des femmes-

il faut déterrer l'amour

/martyres

étouffé dans le dévouement et le mépris

déterrer le désir

humilié dans le silence du corps

déterrer la tendresse

étranglée dans la caresse à double face

trouver l'espoir et l'effort

de notre propre naissance

je veux être cette chaleur pénétrante

pour ne plus avoir froid

je veux que tout pénètre en moi

pour n'avoir besoin de rien

ne jamais avoir besoin

je veux m'aimer tout à fait

pour être une grande porte ouverte

et ne plus connaître le sexe-prison 
je n'suis pas un vide un gouffre un abîme un creux un silence sur qui on peut compter je n'tairai pas le sang de l'âme enfourchée

je $n$ 'suis pas un ventre laboratoire une usine gratuite à engrosser à récolter à oublier

je n'suis pas un nid une maison un lit défait et refait un remède une assiette quotidienne sur qui /on peut compter

je n'suis pas non plus un rêve inatteignable une bonne fée un mirage une image qui s'humilie un secret un barbouillage un saccage de mon immensité je n'veux plus être chambre fermée à double tour depuis toujours et pour toujours

je n'veux plus me farder l'âme m'épiler l'coeur m'désodoriser l'sexe me teindre la pensée m'éteindre la parole

je veux être cette chaleur pénétrante pour ne plus avoir froid ne plus avoir peur de moi

je veux que tout pénètre en moi pour $n$ 'avoir besoin de rien ne jamais avoir besoin je veux être cette chaleur pénétrante pour que l'amour n'aie besoin de rien et devienne I'INSTINCT de l'espoir 
une eau claire coule en moi

qui promet la débâcle de l'inconnu

une eau vive surgit dans ma mémoire

l'enfant que j'ai été

ce rire qui veut revivre

ce regard grand comme deux grandes cibles offertes

cette "force d'être" intuable

cet élan d'un bout à l'autre du corps

réclame de refaire surface

réclame la femme que je suis

cette eau vive cette inconnue qui vient surgir

me ressemble plus que celle que vous connaissez

je l'ai cherchée depuis toujours en dehors de moi

je l'ai en moi depuis toujours

qui veut fendre le jour et naître 



\section{MOMAN}

moman tu cries dans mon âme

tu hurles une longue plainte envahissante

qui s'exagère s'exaspère

et se perd dans le vide

ma rage étouffe dans tes grandes ailes habituées

mon sang femelle a coulé de honte

dans ta complice douleur

j'ai lu dans ta complice douleur

le sacrifice qui m'était dû

l'insulte à l'élan magique de mes désirs

moman au bout de tes doigts

dix griffes à gratter les taches

dix griffes à t'arracher l'âme

de l'écran quotidien

mes griffes se cachent dans tes grandes ailes habituées

nous écoulons le fleuve de vie

en larmes inutiles

pendant que le fleuve de feu

qui gronde sa fierté

meurt dans la honte de notre propre sang

bouche du sexe comme un vide apparent

qui hante la honte

bouche de la parole cousue dans la confidente confinée au silence

mon enfance s'oublie dans tes grandes ailes habituées 
il me faut te trouver

en dehors d'un silence

qui s'en prend à lui-même

il me faut te recontrer

quelque part en dehors

d'une cachette qui chuchote

en dehors

d'une chambrette qui murmure te rencontrer

quelque part au sommet de nous-mêmes

à la vue de tous

nos voix comme des grands navires

des grandes fusées

à la conquête

de I'ENFANT-FEMME

moman qui peut nous comprendre

si nous ne jaillissons pas

en dehors de la peur

j'ai eu peur de toi peur de moi

j'ai voulu $\mathrm{m}^{\prime}$ exorciser de toi

te fuir te renier $t^{\prime}$ oublier

mais j'ai failli nous perdre

dans le refus silencieux

qui se glisse sournoisement

et $s^{\prime}$ installe pour la vie

je n'ai pas pu nous fuir

le miroir était là 
dans la grande nuit blanche que j'ai traversée

somnambule vide

à peine visible de corps

sur la corde de la folie

j'ai appelé la femme d'où je suis née

moman de mon grand trou-vagin sans nom

je t'ai aperçue en dessous d'une montagne de dévouement je t'ai aperçue enfin toi

I'ENFANT-FEMME encore en espoir

I'ENFANT-FEMME qui boit

dans les cachettes souterraines

la force de renaître

du grand tunnel de ma mémoire

j'ai vu I'ERREUR de I'HISTOIRE

le COMPLOT de la PEUR

j'ai vu la main d'homme

qui vient planter entre nos côtes

la croix de sa découverte

faire de nous

la terre de ses exploits

j'ai vu les femmes porter leurs croix en silence

chaque femme aidant l'autre

à se mourir dans l'autre

moman il faut exorciser la crainte

il faut forcer le destin à avouer le meurtre de notre liberté

la vie se tait dans nos grandes ailes habituées

la vie se meurt dans I'OEUF 
il est sorti de la magie de ma mémoire

un petit être rouge vif foetus de ma naissance

embryon de moi-même

je me suis regardée en plein soleil de midi

j'ai reconnu mon corps pour mien

la grotte sombre et inquiète

retrouvait la vérité de sa matière

dans vallons et montagnes de notre chair

s'ouvre un passage insoupçonné

une ouverture qui n'a rien d'un abîme

c'est l'ENFANT-FEMME

qu'on avait égorgée au début des temps

ENTRAILLES D'ARCHES ET DE VOÛTES DE FEU

DOUCES ET PARFUMANTES

UNE ÉNORME ET PROFONDE CARESSE

DE MA CHAIR À MA CHAIR

j'y ai retrouvé ma terre d'origine

j'y ai reconnu le lieu de ma naissance

enfin je viens de quelque part

qui n'est pas un vide rond ensemencé

moman l'enfant que tu as été est venue me rejoindre

à l'aube de ma conscience

j'avais l'impression d'y reconnaître ma fille

je t'ai vue ma mère-enfant

qui crie en moi depuis toujours

tu m'es rendue intacte

dénuée de tout dévouement

extirpée de la longue plainte infinie

de l'Histoire de nos mères

ballon d'enfant qui roule vers la mer

promesse de retrouver la VAGUE-MAITTRESSE 
moman tes grandes ailes soumises ne te ressemblent pas je n'veux plus de cettes mascarade domestique qui refuse de voir les vrais visages

tes grandes ailes

c'est pour planer au-dessus de toute contrainte

tes grandes ailes protectrices

se sentent coupables d'elles-mêmes

tes grandes ailes c'est pour voyager

c'est pour l'aventure

tes grandes ailes c'est pour être grandes

pour être vivantes

c'est pour être telles quelles

enivrées de nous-mêmes

ENFANTS-FEMMES AUX GRANDES AILES DÉPLOYÉES

DES PREUVES DE NOTRE NAISSANCE 